\title{
Investigation of the Nitrogen Content of Wheat According to Changing Meteorological Factors by Hermes Model
}

\author{
Sami Kaya ${ }^{1}$, Elif İnan', Nilcan Altınbaş ${ }^{1}{ }^{*}$, Barış Çaldağ ${ }^{1}$, Levent Şaylan ${ }^{1}$ \\ ${ }^{1}$ Istanbul Technical University, Faculty of Aeronautics and Astronautics, Department of Meteorological \\ Engineering, Istanbul, TURKEY
}

\begin{abstract}
Ongoing increases in global population and expanding settlement areas brought by this situation have important results like decreasing farmlands. Hence, it has great importance to increase the yield rates obtained from the unit area. As well known, crop yield is mainly affected by nitrogen content of soil and plant. Thus, in this study, it was aimed to investigate the nitrogen content in a wheat cultivated field by the help of a HERMES crop model by using some meteorological parameters collected from an experimental site in Kırklareli City of the Thrace Region located in northwestern part of Turkey. In this frame, possible effects of variations in meteorological parameters were simulated using the model. Variations in nitrogen content were determined under consideration of the winter wheat crop grown. Results were evaluated by means of the analysis of both plant and soil nitrogen contents.
\end{abstract}

Key words: Mineralization, Climate Change, Yield, Winter Wheat

\section{INTRODUCTION}

Nitrogen is an essential nutrient for agricultural production. Plants need nitrogen to increase their biomass and become mature. Under the conditions with nitrogen deficiency, plants cannot grow normally, stays dull. The leaves of the plant become small, yellow or yellowish green. The lower or older leaves die by drying. In this situation, flowering is also not normal and crop yield decreases. Thus, determining the enough nitrogen amount that the soil should contain to make plants grow in a healthy way.

Plants reaches the nitrogen which is a gas covering $78 \%$ of the atmosphere, by two different ways. One of these is the transmission of nitrogen in the air to the soil, and the second is the bacteria that bind nitrogen to the soil. Bacteria at the roots of legumes transmit this nitrogen from the nodules found at the roots of the legumes and use this nitrogen. In addition, meteorological events such as lightning and rain are transmitted to the nitrogen soil. Another factor that transports nitrogen to the plant is organic matter mainly composed by plants and animal wastes, falling to the soil. Organic materials that decompose into soil turn into nitrogen and are taken up by the plant. The biomass of plants has a direct relationship with nitrogen. They grow up with the nitrogen that they receive from the soil. Another factor directly related to the development of plants is meteorological factors.

In recent years, the relationship between agricultural meteorology and production has begun to be examined with various simulation models. In many countries, plant climate simulations are used to predict the possible effects of climate change on crop production and to determine the advantages and disadvantages of these changes to take necessary precautions in order to raise the yields of agricultural products. In this paper, this relationship was examined with the HERMES model which is first used to simulate crop growth and nitrogen dynamics (Kersebaum, 1995). HERMES model was created for common sense purposes (nitrogen fertilizer recommendations, nitrogen leaching assessment, land use evaluation) in the field of horticulture, water insurance and land utilize arranging. (Kersebaum, 2007). Since the model was developed, it has been

\footnotetext{
*Corresponding author: akatas@itu.edu.tr
} 
widely used a useful tool for many agrometeorological studies in literature. For instance, Palosuo et al. (2011) used the model in a comparative study including eight crop models to simulate winter wheat yield for different climates of Europe. Model predictions were in good agreement with observed yields but some overestimations of yield values appeared and calibrations were applied. There is also a similar study comparing nine different crop model and again including HERMES model applied to determine spring barley yield in Northern and Central Europe (Rötter et al., 2012). According to model results, HERMES is one of the three model having the lowest error values and most accurate yield estimation. Graß et al. (2015) used the model to simulate crop development and water and $\mathrm{N}$ progression in arable fields under very different climate conditions from Canada to Australia, Argentina, Brazil, Tanzania and India. It was proficient to react appropriately even on extraordinary heat stretch. In another study, HERMES was coupled with GIS to investigate its performance to simulate spatial variability of crop yield and nitrogen dynamics (Kersebaum, 2005). Considering the results, HERMES is able to give accurate results for heterogeneous areas unless there is high small scale variability of observations and uncertainties of input data.

In this study, measured and observed agrometeorological data from the experimental field of Kirklareli City located in Thrace region of Turkey was used to derive the HERMES model simulations in order to understand the impacts of meteorological factors on winter wheat crop during growing season including the stages from planting up to the ends of tillering. This field was chosen because Kirklareli is a region with high agricultural potential and importance for Turkey.

\section{MATERIALS AND METHODS}

HERMES crop growth simulation model was performed in the study to analyze effect of meteorological factor on crop growing and yield. Observed data that HERMES model requires was collected from the experimental field of Atatürk Soil Water and Agricultural Meteorology Research Institute Directorate in Kirklareli in the Thrace Region of Turkey. Thrace is a region with high agricultural potential and proximity to industrial regions, which is required to be investigated for phenology and drought (Çaldağ and Şaylan, 2011). Soil data as an input for HERMES model, belong to the same experimental field in Kirklareli.

\section{Model Description}

The model HERMES was developed for the simulation of $\mathrm{N}$ dynamics within the framework of plant and soil system. The model simulates soil water and $\mathrm{N}$ dynamics as well as crop growth and $\mathrm{N}$ uptake by the crop (Kersebaum, 1995). Model needs the meteorological data including air temperature, precipitation and global radiation; soil data for each $10 \mathrm{~cm}$ of profile; and management data including crop type, dates of agricultural activities such as sowing and fertilization.

The model allows the simulation of different crops which are parameterized by external crop parameter files which are included in the model package were proved at single experimental data (Kersebaum, 1995).

\section{Field Data}

The phenological stages of the winter wheat during growing period for 2009-2010 are given in Table 1. Growing season of the crop is divided by 10 main period according to the dates reference to the observed development stages of the crop. The date of 
planting and harvest used as inputs for model simulations.

Fertilization type, date and amount information can be found in Table 2. In addition, soil texture information of experimental field is given in Table 3.

Table 1. Phenological stages of winter wheat crop in 2009-2010 growing season.

\begin{tabular}{cc}
\hline Winter Wheat & Date \\
\hline Planting & 09.10 .2009 \\
Germination & 17.10 .2009 \\
$2^{\text {nd }}$ leaf & 21.10 .2009 \\
$3^{\text {nd }}$ leaf & 26.10 .2009 \\
Tillering & 25.11 .2009 \\
Stem formation & 31.03 .2010 \\
Earing & 26.04 .2010 \\
Flowering & 10.05 .2010 \\
Maturity & 04.06 .2010 \\
Harvest & 06.07 .2010 \\
\hline
\end{tabular}

Table 2. Fertilization information

\begin{tabular}{ccc}
\hline Fertilizer & Date & Amount \\
\hline Urea & 09.10 .2009 & $10 \mathrm{~kg} / \mathrm{da}$ \\
Urea & 03.03 .2010 & $15 \mathrm{~kg} / \mathrm{da}$ \\
Ammonium & & \\
Nitrate $\left(\mathrm{NH}_{4} \mathrm{NO}_{3}\right)$ & 08.04 .2010 & $25 \mathrm{~kg} / \mathrm{da}$ \\
\hline
\end{tabular}

\section{RESULTS}

The HERMES model simulations were derived by different scenarios including temperature and precipitation changes. In order to understand the influences of meteorological parameters on crop growth, effects of temperature changes on water content, nitrogen content and mineralization were investigated at first. Secondly, effects of precipitation changes on the same three parameters were examined. Then, it was aimed to determine the effects of temperature and precipitation on crop yield.

\section{Temperature Change Scenario}

In this scenario, the average temperature was calculated considering each phenological stage turning day. Then temperature values were changed by average temperature values. The calculated average value assigned instead of each day's measured value and differences were analyzed for water content, nitrogen content, mineralization and crop yield

Table 3. Soil texture

\begin{tabular}{|c|c|c|c|c|c|c|c|c|c|}
\hline $\begin{array}{l}\text { Soil depth } \\
\text { (cm) }\end{array}$ & $\begin{array}{c}\text { Saturation } \\
(\%)\end{array}$ & $\mathrm{pH}$ & $\begin{array}{c}\mathrm{CaCO}_{3} \\
(\%)\end{array}$ & $\begin{array}{c}\mathrm{P} \\
(\mathrm{kg} / \mathrm{da})\end{array}$ & $\begin{array}{c}\mathrm{K} \\
(\mathrm{kg} / \mathrm{da})\end{array}$ & $\begin{array}{l}\text { Clay } \\
(\%)\end{array}$ & $\begin{array}{l}\text { Silt } \\
(\%)\end{array}$ & $\begin{array}{c}\text { Sand } \\
(\%)\end{array}$ & $\begin{array}{l}\text { Weight } \\
(\%)\end{array}$ \\
\hline $0-30$ & 44 & 7.67 & 2.2 & 22.07 & 84.69 & 12.50 & 20.83 & 66.67 & 16.20 \\
\hline $30-60$ & 59 & 7.63 & 1.5 & 32.06 & 60.69 & 18.75 & 27.08 & 54.17 & 16.85 \\
\hline $60-90$ & 57 & 7.77 & 1.5 & 34.86 & 55.52 & 16.67 & 27.08 & 56.25 & 22.82 \\
\hline $90-150$ & 49 & 7.71 & 9 & 30.31 & 64.21 & 16.67 & 25.00 & 58.33 & 22.56 \\
\hline
\end{tabular}

\section{Effect of Temperature Change}

When measured temperature values were switched with the average temperatures, volumetric water content percentage of soil became slightly higher (Figure 1). The greatest deviation from the average of the temperatures was found in tillering period. If temperature values changes with the averages in this period, due to higher volumetric water content values, growing crop can reach more water to throw up.

Temperature changes affect nitrogen contents of soil obviously. When average temperature values are used instead of 
measured values, nitrogen content and mineralization of soil are quite low (Figure 2-3). This effect mainly influences on the amount of nitrogen uptake from soil to be growth. Thus, crop height is affected by this situation.

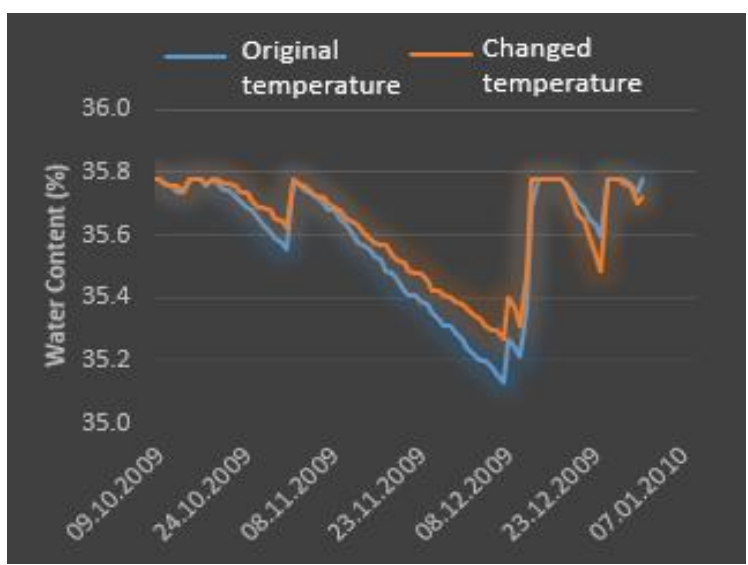

Figure 1. Temperature change effect on volumetric water content

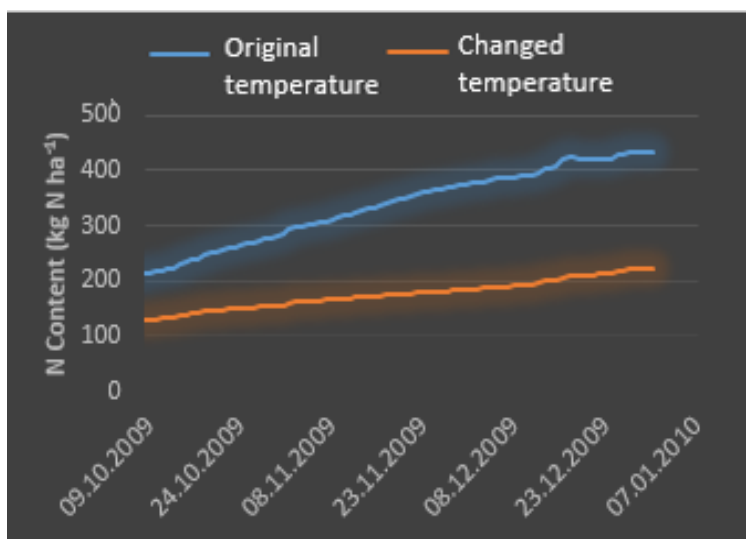

Figure 2. Temperature change effect on nitrogen content

The effects of temperature changes on mineralization have showed a similar result with the nitrogen content. The average temperatures caused slightly lower mineralization values. Mineralization reduced the nitrogen content that crops can take from soil by their roots, so that the growing of crop may affect negatively if there is less or no more available nitrogen in the soil.

Considering all these effects, crop yield changes were analyzed. With observed temperatures, crop yield has continued at the same value while changed temperatures

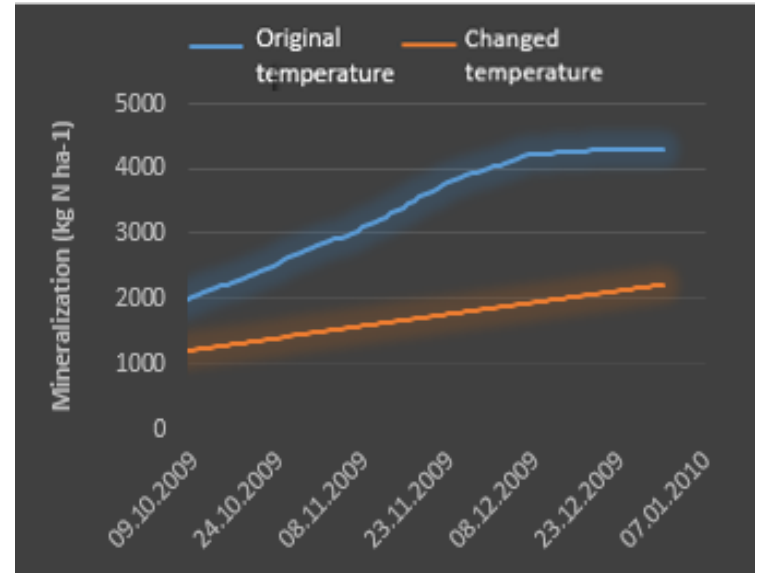

Figure 3. Temperature change effect on mineralization

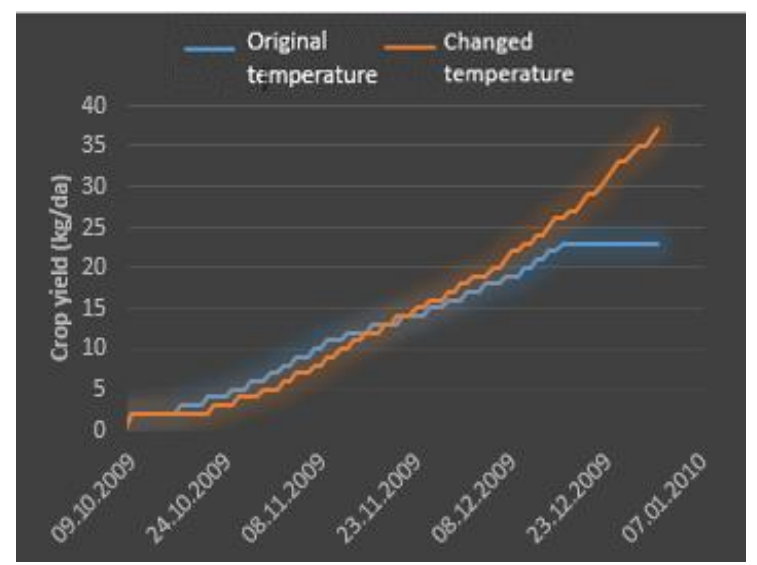

Figure 4. Temperature change effect on crop yield

caused constantly increased values (Figure 4.). In real situation, crops growth remains after some time during growing period. Yet, the model may not simulate the real situation considering different growing periods.

\section{Effect of Precipitation Change}

In the model simulations, precipitation values doubled in order to understand the change of precipitation effects for crop growth and then compared to the original precipitation data from planting day.

Figure 5 shows the precipitation effects on the volumetric water content of soil. Unfortunately, the model did not give meaningful results when precipitation values 
doubled. However, in real, water content fluctuations can be seen clearly. Water content takes minimum value at the end of the tillering stages of winter wheat growing season. In $2^{\text {nd }}$ leaf period, it takes the maximum value. High available water content percentages cause the crop growing positively especially in the earlier periods.

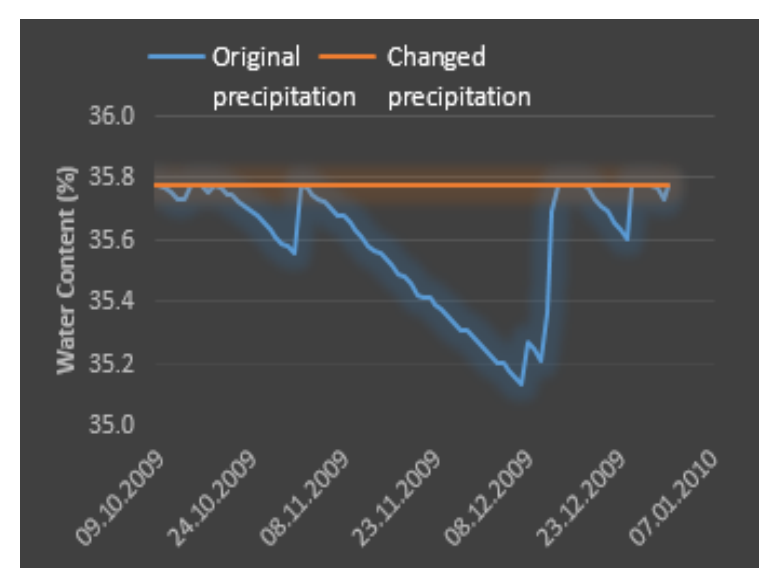

Figure 5. Precipitation change effect on volumetric water content

When doubled precipitation values were used instead of measured values, nitrogen contents of soil were slightly higher than the original situation (Figure 6). Until the beginning of tillering stage, both two values continued the same but later nitrogen contents were higher when doubled precipitation rates exist. Higher precipitation caused higher nitrogen content according to the model simulations.

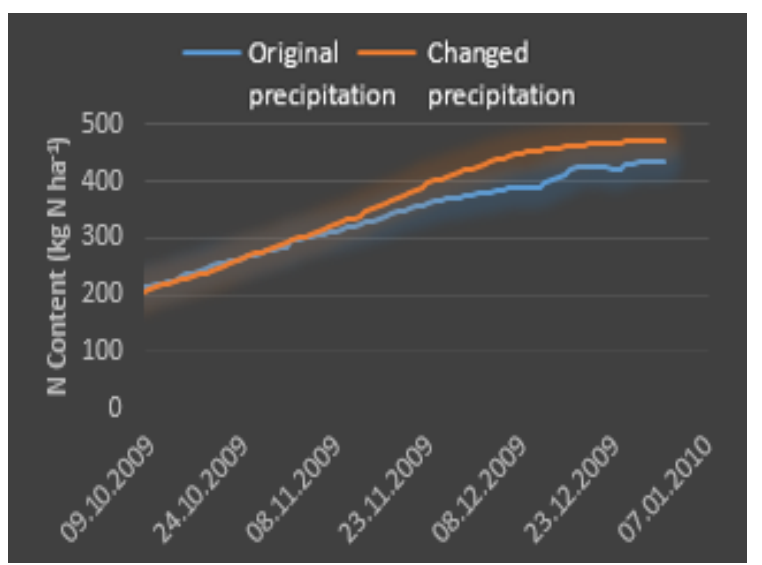

Figure 6. Precipitation change effect on nitrogen content
Mineralization values are not different for both precipitation scenarios used in the model. The values were generally overlapped during whole period as can be seen in Figure 7. Model results showed that precipitation does not affect much the mineralization rates.

Crop yield results were also like mineralization results. For both two precipitation scenarios, crop yield values behaved same on the graph. Only at the end of considered period, while crop yield remained same for the original situation, it progressed in increasing in the doubled precipitation scenario (Figure 8).

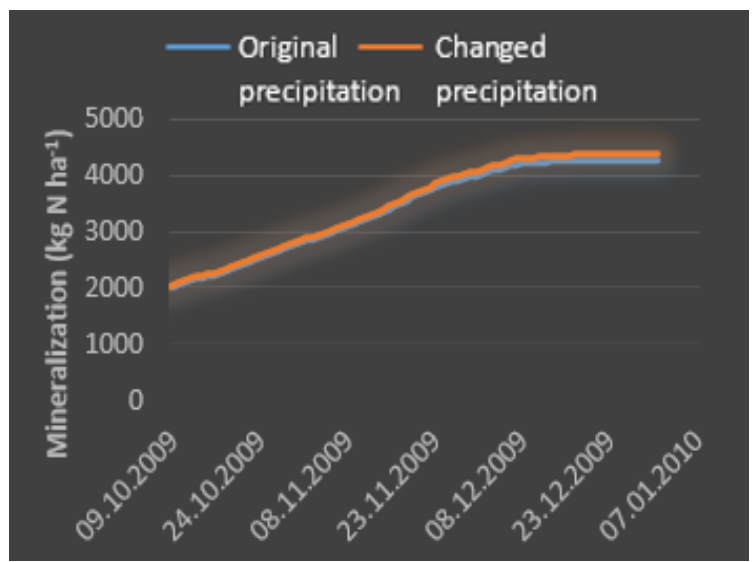

Figure 7. Precipitation change effect on mineralization

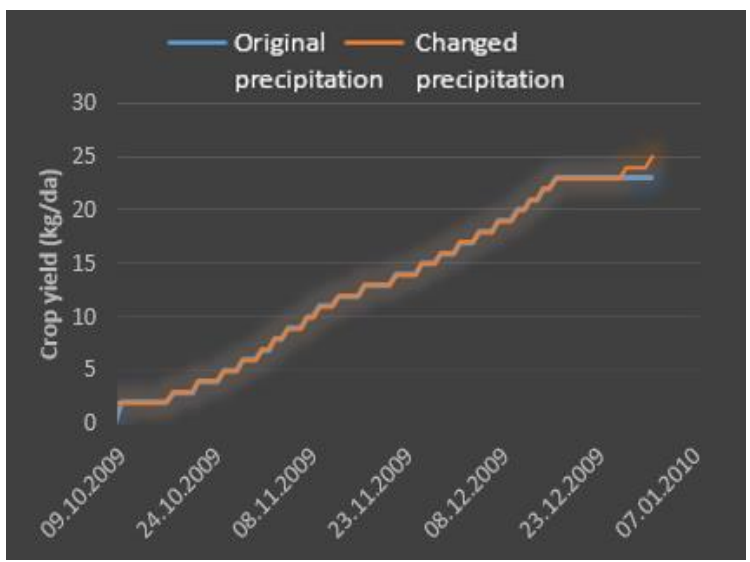

Figure 8. Precipitation change effect on crop yield 


\section{CONCLUSION}

In this study, HERMES crop growth simulation model were performed under different scenarios including temperature and precipitation changes. It was aimed to determine that how these changes affect the rates of volumetric water content, nitrogen content, mineralization content and crop yield. According to the model results, these four parameter are mainly affected by the temperature changes. Precipitation changes has also influences on these parameters. Even little changes may affect positively or negatively the crop growth, defining optimum soil and meteorological conditions are quite significant for this kind of agricultural studies. Thus, simulation results have to be developed and supported by the field studies.

\section{ACKNOWLEDGEMENTS}

We would like to thank to Atatürk Soil Water and Agricultural Research Institute Directorate employees providing meteorological and soil data for this study.

\section{REFERENCES}

Çaldağ, B., Şaylan, L. (2011). İklim değişiminin buğday verimine etkilerinin incelenmesi: Kurklareli örneği. $\quad \dot{I T U}$ Dergisi: 9/5: 107-112.

Graß, R., Thies, B., Kersebaum, K. C., Wachendorf, M. (2015). Simulating dry matter yield of two cropping systems with the simulation model HERMES to evaluate impact of future climate change. European Journal of Agronomy, 70, 1-10.

Kersebaum, K. C. (1995). Application of a simple management model to simulate water and nitrogen dynamics. Ecological Modelling, 81 (1995), pp. 145-156.

Kersebaum, K. C., Lorenz, K., Reuter, H., Schwarz, J., Wegehenkel, M., Wendroth, O. (2005). Operational use of agrometeorological data and GIS to derive site specific nitrogen fertilizer recommendations based on the simulation of soil and crop growth processes. Physics and Chemistry of the Earth, 30, 59-67.

Kersebaum, K. C. (2007). Modelling nitrogen dynamics in soil-crop systems with HERMES. Nutrient Cycling in Agroecosystems, 77: 39-52.

Palosuo, T., Kersebaum, K. C., Angulo, C. et al. (2011). Simulation of winter wheat yield and its variability in different climates of Europe. A comparison of eight crop growth models. European Journal of Agronomy, 35, 103-114.

Rötter R. P, Palosuo T, Kersebaum K. C et al. (2012) Simulation of spring barley yield in different climatic zones of Northern and Central Europe. A comparison of nine crop models. Field Crops Research, 133, 23-36. 